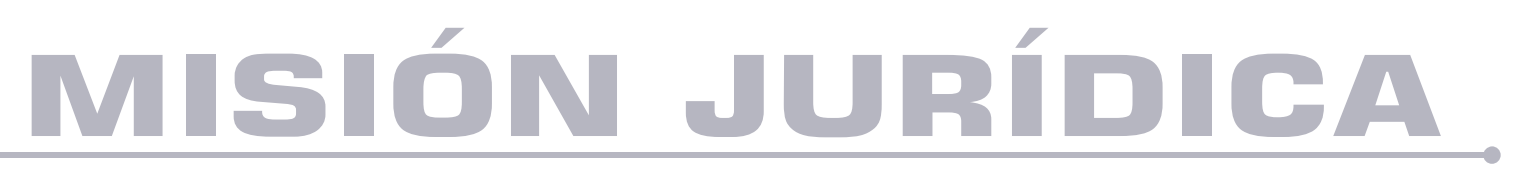

\title{
Una mirada en retrospectiva al ingreso a la nueva época de codificación civil de China
}

A retrospective review on China's entry to the new era of Civil Law Codification

Autor: Yun Li

DOI: https://doi.org/10.25058/1794600X.1947

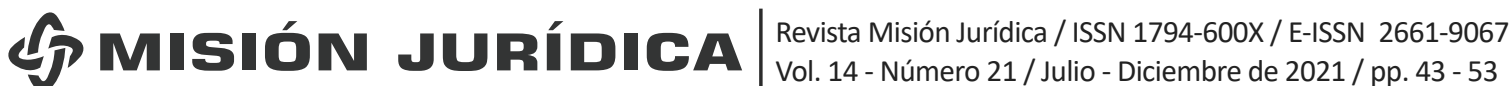




\title{
Una mirada en retrospectiva al ingreso a la nueva época de codificación civil de China*
}

\author{
A retrospective review on China's entry to the new era of Civil
}

Law Codification

\author{
Uma retrospectiva da entrada na nova era de codificação \\ civil da China
}

\author{
Yun $\mathrm{Li}^{\mathrm{a}}$ \\ carfield_9@163.com
}

Fecha de recepción: 3 de abril de 2020

Fecha de revisión: 26 de mayo de 2020

Fecha de aceptación: 20 de octubre de 2020

\section{DOI: https://doi.org/10.25058/1794600X.1947}

Para citar este artículo:

Li, Y. (2021). Una mirada en retrospectiva al ingreso a la nueva época de codificación civil de China. Revista Misión Jurídica, 14(21), 43-53.

\section{RESUMEN}

La historia y cultura jurídica de China, especialmente en la etapa de su Derecho Civil, no cuenta con la codificación de este como tradición y elemento esencial; no obstante, el sueño de completar un Código Civil chino abarca toda su evolución histórica y, para lograr este sueño, se han realizado varios intentos. El Derecho Civil chino muestra sus propias características particulares a lo largo de su desarrollo, en que ha asimilado las ventajas del Derecho extranjero (especialmente del Derecho occidental) y las ha integrado con la tradición jurídica china, como el confucianismo y el legalismo, a fin de adaptarse a las circunstancias económicas y sociales chinas. En este trabajo se responderá cómo se ha desarrollado la tradición del derecho de la Antigua China a la modernización del derecho chino y cómo se han producido estas paulatinas recepción, incorporación e integración del Derecho extranjero en China.

\section{PALABRAS CLAVE}

Perspectiva histórico-cultural; Derecho civil; Código Civil; China; confucionismo; legalismo.

\footnotetext{
${ }^{*}$ Artículo de reflexion.
}

a. Yun Li, doctora en Derecho Privado de la Universidad Autónoma de Madrid y profesora en la Facultad de Estudios Extranjeros de la Universidad China de Ciencias Políticas y Derecho (CUPL, Beijing, China). Dirección postal: Av. Fuxue 27, Universidad China de Ciencias Políticas y Derecho, Changping, Beijing, China. Código postal: 102249. Dirección electrónica: carfield_9@163.com. 


\section{ABSTRACT}

China's legal history and culture, specially in the stage of civil law do not have a codification of civil law as a tradition and essential asset. However, the dream to complete a Chinese Civil Code comprehends its historical evolution and many attempts have been made to achieve this dream Chinese civil law presents its own particular characteristics in its development, in which it has absorbed the advantages of foreign laws (especially western laws), and has combined them with Chinese legal traditions, such as Confucianism and legalism, in order to adapt to China's economic and social conditions. In this research, we will explain how the legal tradition of the Ancient China has turned into the modern Chinese laws and how China has gradually accepted, adopted and incorporated foreign law to its legal system.

\section{KEY WORDS} China.

Historical and cultural perspectives, Civil Code,

\section{RESUMO}

A história e cultura jurídica da China, especialmente na fase de seu Direito Civil, não tem a codificação desta como tradição e elemento essencial; no entanto, o sonho de completar um Código Civil Chinês abrange toda a sua evolução histórica, e várias tentativas foram feitas para concretizar esse sonho. O Direito Civil Chinês mostra características próprias ao longo de seu desenvolvimento, na medida em que assimilou as vantagens do Direito estrangeiro (especialmente o Direito Ocidental) e as integrou à tradição jurídica chinesa, como o Confucionismo e o Legalismo, para se adaptar à economia chinesa e circunstâncias sociais. Neste artigo, vamos responder como se desenvolveu a tradição do direito da China Antiga para modernizar o direito chinês e como se produziu essa gradual recepção, incorporação e integração do direito estrangeiro na China.

\section{PALAVRAS CHAVE}

Perspectiva histórico-cultural; Direito civil; Código Civil; China; Confucionismo; Legalismo.

\section{INTRODUCTION}

La gran obra clásica El Quijote nos cuenta que"la historia es émula del tiempo, depósito de las acciones, testigo de lo pasado, ejemplo y aviso de lo presente, advertencia de lo porvenir" (Barrios et al, 2002, p. 9). Destaca José Sánchez-Arcilla Bernal que "el Derecho es, como parte esencial de la cultura, un producto histórico y, como tal, no puede prescindir de su historicidad"(2001, p. 9).

La doctrina china suele clasificar la evolución histórica del Derecho civil de China en tres etapas: 1) de los finales de la dinastía Qing a la fundación de la República Popular de China, en 1949; 2) desde la fundación de la República Popular de China hasta el año 1982, cuatro años después de la Reforma y Apertura; y 3) de 1982 a hoy en día.

\section{DERECHO CIVIL}

Como es sabido, tanto el Derecho privado de España e Ibero-América, como el de China ${ }^{1}$, se basan de manera irrefutable en la tradición del Derecho continental, conocido también como el Derecho civil.

El Derecho continental o Derecho civil (Civil Law) se basó en el Derecho romano. Apareció y se desarrolló inicialmente en el Continente europeo, de donde toma su nombre (Derecho continental europeo). El Derecho continental también es conocido por el nombre del Derecho civil, porque tanto el Código Civil de Francia, a principios del siglo XIX, como el Código Civil de Alemania, a finales del mismo siglo, han promovido de fuertemente el desarrollo del Derecho Civil.

Hoy en día, el Derecho Civil es uno de los dos grandes sistemas jurídicos que existen. Cubre la mayor parte del mundo, y, entre los países que se rigen por él, se encuentran España, los países de América Latina, y China, etc. (es decir, los países objeto de este estudio).

Al hablar del Derecho civil continental, es imposible omitir el concepto de la codificación, que se considera como una de las características más importantes del Derecho civil continental. Hasta hoy hay bastantes definiciones de la codificación. Aquí se tendrá en cuenta la definición de la codificación dada por el jurista chileno Hernán Corral Talciani, en los siguientes términos: "La codificación es una especie

1. Hong Kong se rige por el Common Law. 
de fijación del Derecho que se caracteriza por innovar respecto de la presentación del material normativo y su organización, por establecer un derecho nuevo que se distancia del anterior, y por determinar la pérdida de vigencia de todas las disposiciones jurídicas anteriores, aunque puedan ser compatibles con la legislación codificada (2007).

Francisco Tomás y Valiente, historiador y jurista español, explicó que:

la obra más importante en la historia del Derecho romano es, sin duda, la recopilación llevada a cabo por el emperador Justiniano entre los años 528 a 533. Estaba integrada por las Instituciones (obra elemental destinada a la enseñanza del Derecho), el Digesto o Pandectas (ingente recopilación de textos de la jurisprudencia clásica), el Código (compilación de constituciones imperiales desde Adriano hasta Justiniano) y las Novelas (constituciones posteriores al Código). Desde el siglo XII y de modo más definitivo a partir de la edición llevada a cabo en 1585 por Dionisio Godofredo, la obra de Justiniano recibe el nombre de Corpus Iuris Civilis (2004, p. 180).

En el norte de Italia, en el siglo XII (probablemente en el año 1135), se halló el manuscrito del Corpus Juris Civilis, que se había perdido durante varios cientos de años a causa de las guerras. Los estudiosos y glosadores lo investigaron y realizaron pruebas y comentarios sobre él en la Universidad de Bolonia, formando la Escuela de Bolonia, también conocida como la escuela de los jurisconsultos boloñeses o escuelas de los Glosadores del Derecho Civil.

En aquel entonces, como el Corpus Juris Civilis era mucho más avanzado que otras leyes del continente europeo, se lanzó un movimiento de renacimiento del Derecho romano en Europa, estudiando y aplicando el Derecho romano. El movimiento del Renacimiento del Derecho Romano provocó que la mayoría de las leyes del continente europeo siguieran el ejemplo del Derecho romano, formando así el prototipo del Derecho Civil.

\section{PRECEDENTES DESTACADOS DEL MODERNO DERECHO CIVIL}

Se encuentra a continuación una breve explicación del papel que los Códigos Civiles europeos más influyentes -el francés y el alemán- han jugado en el desarrollo del Derecho de contratos chino y latinoamericano.

\subsection{El Código Civil francés de 1804 como hito} común en la Historia del Derecho de Contratos

El Derecho civil se considera como el núcleo del Derecho privado y el Código Civil está considerado como el núcleo del Derecho civil. Lo anterior permite reconocer la importancia del Código Civil como "núcleo del núcleo" y entender la importancia que ocupa su codificación en la legislación de un país perteneciente a la tradición del Derecho continental. Como expresa el jurista Hernán Corral Talciani,

desde que Bentham inventara el neologismo "codification", la palabra ha terminado por imponerse para designar el proceso por el cual el Derecho de tradición latino-germánica ha adquirido su forma de presentación actual: los códigos. La idea de que el rol central del código sería neutralizado por la fragmentariedad de una legislación descodificada no parece haber concitado consenso. Por el contrario, la aspiración a codificar como forma de unificación del Derecho a nivel supraestatal indica su subsistencia, como lo demuestran los trabajos para llegar a un código europeo de los contratos (2002, p. 267).

El Código Civil francés de 1804 fue el primer ejemplo conocido universalmente, cuyo prestigio e influencia mundial eran incuestionables. Una de sus características, la generalidad y la interacción de las disposiciones que contiene relativas a un determinado conjunto de hechos (Muñoz, p. 3), se ha convertido en una de las características de la tradición del Derecho Civil (p. 3). El Código Civil francés probablemente sea el más prestigio Código Civil por su carácter pionero.

Como ha expresado el jurista francés Pierre Catala, "el bicentenario del Código civil (francés) ha tenido una inmensa resonancia en la mayor parte de los países que han acogido la codificación, cualquiera sea su lengua" (2007, p. 638).

El jurista chileno Hernán Corral Talciani, en otro de sus trabajos, explica que el Código Civil francés "inaugura [...] la época de la codificación», en el sentido de «una cultura jurídica determinada y [...] una forma de concebir el régimen político, y la relación entre legislador, juez y ciudadano", por más que "ya con anterioridad se hubieran promulgado Códigos como el prusiano y el bávaro" (2007, p. 2). El autor sigue explicando que, 
el Code Civil es expresión así no sólo de un intento por fijar el Derecho vigente, sino una forma de transformar el sistema jurídico. Ideas como la igualdad de la ley para todos los ciudadanos, la eliminación de las diferencias de regímenes jurídicos entre regiones. La consideración de la ley como expresión máxima de la voluntad general y por ello soberana, la sumisión del juez a aplicar la ley como mero portavoz de dicha voluntad al caso particular, la exposición del material normativo en frases breves, claras, contundentes y de acceso incluso para los no letrados, la aspiración de que todo este nuevo derecho sea una emanación de la simplicidad y llaneza de la razón natural aplicada a las relaciones sociales, son todas ideas que subyacen a la codificación como proceso histórico, político y social(2007, p. 2).

La importancia del Código Civil francés para Asia radica en que, en el proceso de la recepción asiática del Derecho extranjero, comenzando por Japón ${ }^{2}$, se eligió, en primer lugar, el Código Civil francés, frente al sistema del Common Law, para la traducción a su lengua nativa y posterior adaptación y recepción. La noción del "Derecho Civil” en Japón y China, proviene de la traducción del Código Civil francés al japonés por el jurista japonés Rinsho Mitsukuri (1846-1897) (Asami, 125). La traducción del Código civil francés al japonés fue la base de la conversión o incorporación del Derecho extranjero al Derecho japonés (Asami, p. 126).

\subsection{El Bürgerliches Gesetzbuch (BGB, Código Civil alemán) de 1900 como modelo de Código Civil para Asia}

La importancia del Código Civil alemán para Asia consiste en que, el Código Civil de algunos países asiáticos, como China $^{3}$ y Japón, recibió una gran influencia del Código Civil alemán. Por ejemplo, el Derecho civil japonés heredó del Derecho civil alemán muchos de sus rasgos. Como afirma el jurista japonés,

parece que la factura del nuevo Código es muy próxima a la del Código alemán. He leído

2. Puede verse en Los sistemas del derecho internacional privado japonés y europeo desde una perspectiva comparada, de Etsuko Asami, su tesis doctoral: "En aquella época, la sociedad japonesa no contaba con la palabra derecho ni deberes hasta a finales del siglo XIX cuando se hizo la traducción del Código civil francés" (p. 125).

3. China tuvo Código Civil antes de la fundación de la República Popular de China (RPC), como se explica a continuación. frecuentemente afirmaciones en este sentido. Es cierto que tanto el primer como el segundo proyecto del Código alemán proporcionaron un material muy valioso a la Comisión codificadora y que fueron muy tenidos en cuenta en las deliberaciones de ésta ${ }^{4}$.

China tenía casi la misma situación histórica y experiencias similares que Japón durante el proceso de recepción del Derecho extranjero en la Dinastía Qing, y también ha tomado muchas referencias directas del Código Civil alemán, tanto en la elaboración del Anteproyecto del Código Civil de la Dinastía Qing de 1911, como en la del Anteproyecto del Código Civil republicano.

Los tres Códigos Civiles (incluidos dos Anteproyectos del Código Civil y un Código Civil) antes de la fundación de la República Popular de China (en adelante, RPC) (el Anteproyecto del Código Civil de la Dinastía Qing de $1911^{5}$, el Anteproyecto del Código Civil republicano ${ }^{6}$, y el Código Civil republicano ${ }^{7}$ del 1929] fueron modelados esencialmente sobre la base del Código Civil alemán (Zhang, 2009, p. 468).

Después de la fundación de la RPC, el resultado del primer intento del Gobierno de la RPC para la elaboración de un Código Civil (el Anteproyecto del Código Civil de 1956) fue modelado sobre la base del Código Civil ruso de 1922 (p. 469)., el cual había tomado como referencia el Código Civil alemán. Por lo tanto, se puede concluir que el Anteproyecto del

4. Traducción de Francisco Barberán, Rafael Domingo, Código civil japonés, Editorial Aranzadi, SA, Navarra, 2006, pp. 30-32.

5. Fue elaborado por el Gobierno de la dinastía Qing y terminado en el septiembre de 1911.

6. Fue elaborado por el Gobierno de la República de China y terminado en el 1925. El Anteproyecto del Código Civil Republicano también estaba modelado e influido, aparte del Código Civil alemán, por el Código Suizo de las Obligaciones de 1911.

7. También se traduce como el Código Civil de la República de China. Fue elaborado por el Gobierno de la República de China terminado y entró en vigor en el 26 de diciembre de 1930. «Después de la fundación de la República Popular de China $(R P C)$, en 1949, este primer Código Civil en la historia china fue abolido en la zona continental; de modo que solo se mantuvo en vigencia de Taiwán». Véase en Zhang, Lihong, "Los últimos avances en la codificación del Derecho civil chino», traducción dirigida por el jurista chileno Patricio-Ignacio Carvajar, Revista Chilena de Derecho, vol. 36 No.3, 2009, p. 468.

«El Código Civil republicano también estaba modelado e influido, aparte del Código Civil alemán, por el Código Suizo de las Obligaciones de 1911». Véase en Zhang, Lihong, "Los últimos avances en la codificación del Derecho civil chino», traducción dirigida por el jurista chileno Patricio-Ignacio Carvajar, Revista Chilena de Derecho, vol. 36 No.3, 2009, p. 468. 
Código Civil de 1956 se heredó indirectamente del Código Civil alemán.

Aparte de los países asiáticos, como China y Japón, el Código Civil de una gran cantidad de países también se ha heredado del Código Civil alemán. Por ejemplo, el Código Civil suizo o el Código Civil italiano, recibieron también su influencia (junto a la francesa).

\section{EL SUSTRATO CULTURAL}

El desarrollo del Derecho chino ha estado marcado por dos corrientes de pensamiento: el Legalismo ${ }^{8}$ y el Confucianismo (Domingo, et al, 2007, p. 79).

El periodo de las Primaveras y Otoños ${ }^{9}$ representa una era en la Historia China, [722 a. C. - 481 a. C.]. Es un tiempo de eruditos y de desarrollo cultural. Igual que la antigua filosofía griega es la fuente del desarrollo de la filosofía occidental, la doctrina de los filósofos pre-Qin es la fuente de la cultura china, antes de su encuentro con la cultura occidental. Durante este periodo, coexistieron dos líneas de pensamiento distintas y contrarias: el legalismo y el confucianismo.

\subsection{El legalismo}

El Legalismo, como escuela filosófica en China, se caracterizó por su visión materialista del mundo, contraria al confucianismo. Representó el interés de los grandes terratenientes y del Gobierno frente a los confucianos, plasmándose en la máxima $E l$ hombre vence al cielo (Wikipedia.org). Los partidarios del Legalismo argumentaron que la ley es base del desarrollo social y defendieron el concepto de la propiedad privada. El Derecho o la ley escrita es un instrumento para organizar la sociedad. Los principales representantes del Legalismo fueron Shang Yang y Han Fei (Domingo, et al, pp. 79-80).

8. Según Rafael Domingo (ED.): fă, "término chino usado ancestralmente para referirse a lo que se denomina en español como derecho positivo, lo que se tradujo en el establecimiento de un régimen legal que debía ser estrictamente obedecido bajo la amenaza de severos castigos" (p.79). En China, fă significa tanto el Derecho como la ley.

9. El periodo de las Primaveras y Otoños representó una era en la historia china entre el 722 a. C. y el 481 a. C. Este periodo toma su nombre de los Anales de primavera y otoño, una crónica del periodo cuya autoría se atribuía tradicionalmente a Confucio. Durante el periodo de las Primaveras y Otoños, el poder se descentralizó. Este periodo estuvo plagado de batallas y las anexiones de unos 170 pequeños estados. El lento progreso de la nobleza resultó en un aumento en la alfabetización; el incremento en la alfabetización animó la libertad de pensamiento y el avance tecnológico. Esta era fue seguida por el periodo de los Reinos Combatientes. http://es.wikipedia.org/ wiki/Primaveras_y_Otoños.
3.2. El confucianismo y su influencia en el contexto jurídico

Como expresa el jurista chino Junwei $\mathrm{Fu}$, "es imposible entender la historia del Derecho civil de China sin el conocimiento del confucianismo. Habiendo dominado el pensamiento chino desde hace casi 2.500 años, el confucianismo ha influido fuertemente en todos los sectores de la sociedad china"(2011).

Aunque hoy día, el confucianismo ya ha perdido su función religiosa, se considera como una filosofía de vida. En la China antigua, el confucianismo jugó un papel muy importante en el desarrollo del Derecho chino. De hecho, en su prestigioso estudio de Derecho comparado, Zweigert y Kötz explican que en el Derecho chino las relaciones sociales constituyen una parte del orden natural y que esta perspectiva se encuentra en la doctrina del confucianismo, lo que ayuda a comprender por qué en el Lejano Este se rigieron poco por leyes y tribunales en la solución de conflictos (1998, p. 288).

El confucianismo es la doctrina filosófica de las enseñanzas de Confucio. Confucio nació el 551 a. C., en el país Lu, de la parte este de China, que actualmente es la ciudad Qu Fu de la provincia Shandong. Confucio dedicaba toda su vida al estudio y la enseñanza de las culturas tradicionales de la China Antigua y a luchar en contra del desorden social de la Dinastía Zhou. Confucio cree en la bondad del ser humano y prescinde de la idea de control social mediante leyes estrictas.

\section{DE LA TRADICIÓN DEL DERECHO EN LA ANTIGUA CHINA A LA MODERNIZACIÓN DEL DERECHO DE CHINA}

Durante toda la historia jurídica china, antes de la reforma del sistema jurídico imperial de la dinastía Qing, la tradición jurídica de la Antigua China se caracteriza por los siguientes tres aspectos:

En primer lugar, al referirse al Derecho chino, se trata de una combinación, o mezcla de todas las leyes, civiles, penales, etc., sin independencia entre ellas.

En segundo lugar, las autoridades prestan más énfasis al Derecho penal, y mucho menos al Derecho civil. El Derecho es, por tanto, eminentemente sancionador.

En tercer lugar, aunque existían bastantes normas relacionadas con el sector civil en la Antigua China, 
la doctrina sistematizada del derecho civil todavía no formaba antes de la reforma de la dinastía Qing, pudiéndose concluir que no había derecho civil en la Antigua China comparándose con el desarrollo del derecho civil en el Occidente. Como se ha mencionado, la principal característica del Derecho civil moderno de China es la incorporación de Derechos extranjeros y la integración de ellos y la tradición jurídica china, como el confucianismo y el legalismo. A continuación, se explica cómo se produce esta paulatina recepción, incorporación e integración en China.

\section{LA REFORMA DEL SISTEMA JURÍDICO IMPERIAL DE LA DINASTÍA QING Y EL ANTEPROYECTO DEL CÓDIGO CIVIL DE LA DINASTÍA QING COMO PRIMER PASO DE LA MODERNIZACIÓN}

Esta reforma ocurrió bajo el contexto de la agresión de las potencias de Occidente y es verdad que se trataba de un movimiento por la salvación nacional a fin de asegurar su supervivencia de la extinción.

Antes de las Guerras del Opio (1834-1860), ocurridas durante la dinastía Qing, el Derecho moderno de China había ido germinando, y son los misioneros religiosos occidentales quienes por primera vez introdujeron los pensamientos y teorías jurídicos occidentales a la Antigua China. Las Guerras del Opio y la derrota de la dinastía Qing en estas guerras jugaron un papel acelerador en el desarrollo del Derecho moderno chino, porque tras ellas el Imperio se vio obligado a liberalizar el comercio con los países extranjeros y a entregar puertos estratégicos al capitalismo anglosajón, dando ocasión de advertir el evidente contraste entre Occidente y China en el ámbito jurídico; de esta forma, ocurrió el acontecimiento de la Reforma Constitucional y Modernización, también llamado en el Occidente como Reforma de los Cien Días, entre el 11 de junio y el 21 de septiembre de 1898, dirigido por varios pensadores reformistas encabezados por Kang Youwei y sus discípulos. Aunque esta reforma resultó cortada de raíz, por la emperatriz Cixi, así se fue introduciendo y desarrollando poco a poco el pensamiento y las teorías jurídicas occidentales en la Antigua China. La población china empezó a tomar la iniciativa de explorar el pensamiento y teorías del Derecho civil occidental.

Al final de la Dinastía Qing, había muchos debates acerca de si se introdujera el Derecho occidental a la entonces China antigua o no. Se distinguen dos escuelas: una defendía la tradición propia jurídica de la China antigua, encabezada por Zhang Zhidong [1837-1909]; la otra era favorable a introducir las experiencias extranjeras jurídicas para adaptar la tradición propia de la antigua China a la occidental, encabezada por Shen Jiaben [1980-1913]. Tras varios años de debates, por fin se impuso esta última escuela.

En el año 1907, el emperador de la decadente dinastía Qing decidió elaborar una legislación civil, comisionando a Shen Jiaben ${ }^{10}$ al que nombra Ministro de Justicia, además de a Yu Liansan e Ying Ruichong, para la reforma del sistema jurídico imperial. Shen Jiaben es considerado como el artífice del establecimiento de las modernas escuelas de Derecho (Domingo, 2007, p. 81).

Durante todo el proceso de esta reforma, Shen Jiaben invitó al jurista japonés Yoshimasa Matsuoka, del sector de Derecho civil, como asesor para dirigir la elaboración del Código Civil imperial de la dinastía Qing. También permitió que profesores japoneses con experiencia en la modernización jurídica de la restauración Meiji fueran invitados a China a dictar seminarios y a dirigir la reforma (Domingo, p. 81).

Como el asesor y dirigente de la elaboración de este Código, Yoshimasa Matsuoka introdujo la teoría del Derecho civil japonés a la legislación de este Código.

Yoshimasa Matsuoka redactó las tres primeras partes de este Código Civil, el resto fue redactado por cuatro graduados chinos de las universidades extranjeras: Zhang Zongyuan, Zhu Xianwen, Gao Zhong y Chen Lu, entre los cuales, uno volvió de Francia, uno de EEUU., y los otros dos se graduaron en las universidades japoneses.

Desde el punto de vista biográfico de sus redactores y asesores, el Anteproyecto del Código Civil de la Dinastía Qing está influido profundamente por el Código Civil Japonés de 1898 (Barberán y Domingo, 2006, p 25); como este último se deriva del Código Civil alemán, se puede deducir que el Anteproyecto del Código Civil de la Dinastía Qing también tiene los antecedentes de Alemania.

10. Según la tradición china, igual que la japonesa, la gente antepone los apellidos, o el apellido, al nombre. Aquí, para no confundirlo, sigo la tradición china y antepongo sus apellidos, o apellido, al nombre. 
Los juristas españoles Francisco Barberán y Rafael Domingo opinan que "con él (el Código civil japonés de 1898), el Derecho japonés se había emancipado de la familia jurídica china a fin de incorporarse a la romana)"(p.25). Después de este periodo, comienza la influencia del Derecho europeo en el Derecho chino, vía Japón.

El Anteproyecto del Código Civil de la Dinastía Qing fue terminado en el septiembre de 1911, constaba de cinco Libros [I. Disposiciones Generales; II. De las obligaciones; III. De los Derechos reales; IV. De la familia; V. De las sucesiones], con la misma estructura del BGB alemán (en total, 36 capítulos y 1596 artículos). La influencia del Derecho alemán en cuanto a los contenidos se produce -sin embargosolo en las tres primeras partes.

El Anteproyecto del Código Civil de la Dinastía Qing fue el primer anteproyecto de código civil en la Historia china, tomando referencia y basándose -como ya se ha dicho- en el BGB alemán y el Código Civil japonés, ambos de la naturaleza capitalista. Este Anteproyecto marcó el primer paso de la codificación y modernización del Derecho civil chino.

El Anteproyecto del Código Civil de la Dinastía Qing enfatiza en las reglas básicas del Derecho civil continental europeo, heredando los principios del Derecho civil de Francia y Alemania. Por ejemplo, el principio de los derechos privados, el principio de la libertad contractual, el principio de la indemnización por negligencia; etc.

Desafortunadamente, este Anteproyecto del Código Civil no entró en vigor, ya que el día 12 de febrero de 1911, la dinastía Qing terminó cuando el último emperador de China, Puyi ${ }^{11}$, abdicó al trono y fue expulsado de la Ciudad Prohibida de Beijing. No obstante, afortunadamente esta experiencia sentó las bases de la codificación de China para integrarse en el mundo del Derecho Civil en el futuro.

\section{EL ANTEPROYECTO DEL CÓDIGO CIVIL REPUBLICANO}

Al principio de la República (1911-1949) de China, los legisladores elaboraron el Anteproyecto del Código Civil Republicano con el modelo del Anteproyecto del Código Civil de la Dinastía Qing y las costumbres civiles y mercantiles, siguiendo

11. Protagonista de la película El último emperador (1987), dirigida por Bernardo Bertolucci el modelo de las cinco partes del Anteproyecto del Código Civil de la Dinastía Qing, y también tomaron la mayor parte del contenido de dicho Anteproyecto. Este Anteproyecto fue terminado en el 1925 por el Gobierno de la República de China.

Luego eligieron el Código Civil japonés como modelo de la futura codificación, cuya justificación fue que "el Gobierno nacionalista se inclinaría por las instituciones provenientes del derecho japonés y alemán. Sun Yat-Sen, padre de la República y fundador del Kuomintang, tenía contactos en el Japón y muchos de los altos líderes nacionales estudiarían en Japón"(Domingo, 2007, p. 82).

Como los redactores del Anteproyecto del Código Civil de la Dinastía Qing eran casi la mitad de los redactores del Anteproyecto del Código Civil Republicano, éstos también eran graduados de universidades japonesas, por lo tanto, el Anteproyecto del Código Civil Republicano también estaba influido profundamente por el Código Civil japonés y, por ende, también por el $B G B$ alemán. Se puede afirmar que el Anteproyecto del Código Civil Republicano fue modelado esencialmente sobre la base del Código Civil alemán.

Las experiencias legislativas acumuladas durante las elaboraciones tanto del Anteproyecto del Código Civil de la Dinastía Qing, como del Anteproyecto del Código Civil Republicano, ofrecieron la base sólida para la siguiente elaboración del Código Civil Republicano chino.

\section{EL CÓDIGO CIVIL REPUBLICANO ${ }^{12}$}

Antes de la promulgación del Código Civil Republicano, es posible afirmar que el Derecho civil tradicional chino se mantuvo bajo la forma de derecho consuetudinario (Zhang, 2009, p. 468). El Código Civil Republicano fue el primer código civil en la Historia china. Fue terminado en el año 1931 por el Gobierno Nacional de Nanjing ${ }^{13}$. Junto al Código Civil Republicano, el Gobierno también redactó el Código Constitucional, el Código Penal, el Código de Procedimiento Civil, etc., formando un sistema

12. También se traduce como el Código Civil de la República de China, que se utiliza en "Los últimos avances en la codificación del Derecho Civil chino» (Zhang, Lihong, Revista Chilena de Derecho, vol. 36 No. 3, 2009).

13. En diciembre de 1928, después del establecimiento del órgano legislativo del Gobierno Nacional de Nanjing, dicho órgano comenzó la redacción del Código Civil Republicano. 
jurídico completo y marcando el fin exitoso del proceso de modernización del Derecho chino.

El Código Civil Republicano se aplicó en las zonas gobernadas por el Partido Guomindang durante 20 años, hasta que en el 1949 el Partido Comunista de China emitió una proclama anunciando la abolición de sistema jurídico del Partido Guomindang, incluido el Código Civil Republicano. Después de la fundación de la República Popular de China del 1 de octubre de 1949, el Código Civil Republicano fue abolido en la zona continental y solamente se aplica en Taiwán.

El Código Civil Republicano tuvo, como los Anteproyectos anteriores, los antecedentes y modelos, principal y esencialmente, del Código Civil alemán (Bürgerliches Gesetzbuch, BGB) y el Código Suizo de las Obligaciones de 1911 (Zhang, 2009, p. 468), si bien estuvo notablemente inspirado en el Código Civil alemán (Domingo, 2007, p. 82).

En conclusión, en los tiempos modernos, con la introducción de la teoría del Derecho civil extranjero, se inspiró e inició la difícil exploración de los sistemas continentales europeos, (desde el Anteproyecto del Código Civil de la Dinastía Qing, pasando al Anteproyecto del Código Civil Republicano, hasta el Código Civil Republicano), con influencia particular del Código Civil alemán.

\section{LOS INTENTOS DE CODIFICACIÓN DESDE LA FUNDACIÓN DE LA REPÚBLICA POPULAR DE CHINA (RPC) DE 1949, HASTA LOS AÑOS ALREDEDORES DE LA REFORMA Y APERTURA DE CHINA DE 1978}

Desde la fundación de la República Popular de China (RPC) de 1949 hasta la Reforma y Apertura de China de 1978, el Gobierno de la República Popular de China realizó dos intentos de elaboración de un Código Civil: en 1954 y en 1964, luego un año después de la Reforma y Apertura, intentaron la tercera vez de la codificación.

Después de la fundación de la RPC, empezó "un nuevo proceso de transplante de leyes, esta vez privilegiando a la Unión Soviética, en detrimento del molde occidental" (Domingo, 2007, p. 82). De esta manera, como destaca el jurista chino Zhang Lihong, "el primer intento de elaboración de un Código Civil empezó en 1954 y terminó dos años después con un anteproyecto modelado sobre la base del Código Civil ruso" (2009, p. 468) en el diciembre de 1956.
Este Anteproyecto contaba con 525 artículos, distribuyéndose en cuatro tomos: 1) Disposiciones Generales; 2) Propiedad; 3) Obligaciones; 4) Sucesiones. Desafortunadamente, estas cuatro partes no formaron un único Código Civil integral, sino se convirtieron en cuatro libros separados respectivamente. Al final, estos tomos separados tampoco fueron aprobados por la Asamblea Popular Nacional de China.

A finales de la década de los 50 del siglo XX, empezó la ruptura de la relación entre la Unión Soviética y la República Popular de China, bajo este contexto histórico que obligó la RPC a liberarse tanto del modelo soviético como de la influencia occidental y capitalista, en el siguiente intento de codificación civil, iniciado en febrero de 1964 y terminado en el julio del mismo año, "el legislador chino por primera vez no tomó referencia de ningún Código Civil extranjero" (Zhang, 2009, p. 469). Este anteproyecto contaba con 262 artículos distribuyéndose en tres partes: Disposiciones Generales; Propiedad de bienes, que equivale a la parte Propiedad de otros Códigos Civiles; y, Transmisión de bienes, que no es lo mismo de la parte de los Contrato de otros Códigos Civiles. En este Anteproyecto, «desde los principios de la Historia moderna china, por supuesto, este Anteproyecto "prácticamente estuvo desprovisto de disposiciones jurídicas y, en su lugar, fue integrado por eslóganes políticos"» (Zhang, 2009, p. 469).

Un año después de la Reforma y Apertura, intentaron la tercera vez de la codificación y salió el Anteproyecto nuevo, contando con 283 artículos distribuidos en tres tomos.

\section{LOS ÚLTIMOS AVANCES EN LA CODIFICACIÓN DEL DERECHO CIVIL CHINO $^{14}$}

China todavía no cuenta con un Código Civil, aunque existió en su día y por tanto la codificación del Derecho civil tiene historia desde la Dinastía Qing, con el Anteproyecto del Código Civil de la Dinastía Qing (Yongjun, 2004, pp. 18-19). En todo caso, como antes se explicó, en China rigen los Principios Generales de Derecho civil, de 1986 ${ }^{15}$; y la Ley de Contratos de 1999.

14. Zhang Lihong, «Los últimos avances en la codificación del Derecho Civil chino», Revista Chilena de Derecho, vol. 36 No. 3 , 2009, p. 473 y ss.

15. Los PGDC fueron promulgados en la cuarta sesión del Comité Permanente de la sexta Asamblea Popular Nacional del 12 de abril de 1986 y entró en vigor el 1 de enero de 1987. Datos de www.wikipedia.org. 
El cuerpo del Derecho civil lo constituyen, junto a los textos anteriores, la Ley de Matrimonio, de 198016; la Ley de la Responsabilidad Civil Extracontractual, de $2009^{17}$ la Ley sobre Derechos Reales, de $2007^{18}$, etc.

Muchos juristas chinos han explicado por qué no hay un Código Civil en China hasta la fecha. La codificación del Derecho civil de China siempre ha sido un sueño para los civilistas chinos de varias generaciones y para lograr este sueño, se han realizado varios intentos.

El gobierno chino se decidió a elaborar el Código Civil en la Cuarta Sesión Plenaria del Decimoctavo Comité Central en octubre de 2014. Luego el 15 de marzo de 2017, durante la quinta sesión de la duodécima Asamblea Popular Nacional de China se aprobaron las Disposiciones Generales de Derecho Civil de la República Popular de China (en inglés: General Provisions of the Civil Law of the People's Republic of China), que entraron en vigor el 1 de octubre del mismo año, a través de la Orden Presidencial No. 66 y las mismas se convertirán en el Tomo

16. Aquí se refiere a la nueva Ley de matrimonio de 1980. La vieja Ley de matrimonio entró en vigor el 1 de mayo de 1950, fue la primera ley promulgada después de la fundación de la República Popular de China. Luego, la nueva Ley de matrimonio fue promulgada en la tercera sesión del Comité Permanente de la quinta Asamblea Popular Nacional del 10 de septiembre de 1980 y entró en vigor el 1 de enero de 1981, mientras que la vieja Ley de matrimonio de 1950 fue derogada simultáneamente. La nueva Ley de matrimonio fue modificada por el documento titulado "Decisión sobre la modificación de la "Ley de matrimonio de la República Popular de China"', emitido en la XXI sesión del Comité Permanente de la novena Asamblea Popular Nacional del 28 de abril de 2001. Después, el Tribunal supremo de China emitió la interpretación judicial más reciente el 12 de agosto de 2011.

17. Fue promulgada en la duodécima sesión del Comité Permanente de la undécima Asamblea Popular Nacional del 26 de diciembre de 2009 y entró en vigor el 1 de julio de 2010.

18. Fue promulgada por la quinta sesión del Comité Permanente de la décima Asamblea Popular Nacional del 16 de marzo de 2007 y entró en vigor el 1 de octubre de 2007. de Disposiciones Generales del futuro Código Civil de China. En la quinta sesión y las siguientes sesiones de la décima tercera Asamblea Popular Nacional de China, se solicitó la revisión de los anteproyectos de los tomos de Propiedad, Contratos, Matrimonio y Familia, Sucesiones, etc., a fin de completar el futuro Código Civil de China en 2020 .

\section{CONSIDERACIONES FINALES}

El sueño de completar un Código Civil chino abarca toda la evolución histórica del Derecho civil de China y para lograr este sueño, se han realizado varios intentos de codificación civil en China, fuertemente influidas por las situaciones políticas y económicas del ámbito nacional e internacional. Estas experiencias demuestran la estrecha relación entre la evolución histórica del Derecho Civil chino y los cambios políticos, económicos y sociales.

Como destaca el jurista José Sánchez-Arcilla Bernal, "el Derecho es un instrumento configurador y ordenador de la sociedad, por ello, no es posible un conocimiento de la sociedad -pretérita o actual- sin la comprensión del fenómeno jurídico". Los intentos de codificación civil en China han jugado un papel muy importante en la gobernanza del Estado y la administración de la sociedad para asegurar a nuestra patria el buen orden y la estabilidad.

De acuerdo con José Sánchez-Arcilla Bernal para quien "la historia del derecho no sólo nos suministra información sobre la sociedad del pasado, sino que también, al mismo tiempo, nos permite el conocimiento científico del derecho actual" y futura, de esta manera, se tiene una gran esperanza en la última codificación civil de China y, seguramente este intento conllevará y perfeccionará la innovación de la gobernanza del Estado y la administración social de China en la nueva época.

\section{BIGLIOGRAFÍA}

- Asami, E. (2013). Los sistemas del derecho internacional privado japonés y europeo desde una perspectiva comparada. (Tesis doctoral). Universidad Complutense de Madrid.

- Barberán, F., y Domingo, R. (2006). Código civil japonés, Navarra: Editorial Aranzadi.

- Barrios P., F.; Domínguez N., J. C.; y Maqueda A., C., (2002). Textos de Historia del Derecho Español, Madrid: Editorial Universitas.

- Catala, P. (2007). Presentación general del Anteproyecto, Anuario de Derecho Civil, 
Tomo LX, Fascículo II, abril-junio, 2007, Madrid: Ministerio de Justicia, Ministerio de la Presidencia, Boletín Oficial del Estado

- Corral T., H. (2007). "La descodificación del Derecho Civil en Chile". El Código Civil de Chile (1855-2005). Trabajos expuestos en el Congreso Internacional celebrado para conmemorar su promulgación (Santiago, 3-6 de octubre de 2005), A. Guzmán B. (Edit.). Santiago: LexisNexispp.641-651. También disponible en http://corraltalciani.files. wordpress.com/2010/05/descodificacion. pdf.

- Corral T., H. $<<$ Recensión a la obra de Alejandro Guzmán Brito: "La codificación civil en Iberoamérica. Siglos XIX y XX">>, Anuario de Derecho Civil, tomo LV, fascículo I, (enero-marzo, 2002).

- Domingo, R. (Ed.), Santiváñez, M., Zambrana, N., Caicedo, A., Miranda, A., y Ngo, S. (2007). China, el dragón rampante: panorama político, económico y jurídico, Navarra: Editorial Aranzadi.

- Fu, J. (2011. Modern European and Chinese
Contract Law, A comparative study of party autonomy, Wolters Kluwer, The Netherlands.

- Ge, Y., y Lei, Ch. "Fa Xue Jie Li Tui Zhong Guo Min Fa Dian Chong Zhuang Shang Zhen". Fa Zhi Zhou Mo, (7 de noviembre de 2012).

- Muñoz, E. (2011). Modern law of contracts and sales in latin America, spain and Portugal (International commerce and arbitration), Vol. 6, Chicago: Eleven International Publishing.

- Sánchez-Arcilla B., J. (2001). Historia del Derecho español. Barcelona: Cálamo.

- Tomás y Valiente, F. (2004). Manual de historia del Derecho español. Madrid: Editorial Tecnos

- Yongjun, L. (2004). Derecho de los contratos, Beijing: Law Press de China.

- Zhang, L. "Los últimos avances en la codificación del Derecho Civil chino", Revista Chilena de Derecho, 36 (3), ,

- Zweigert, K. y Kötz, H. (1998). An introduction to Comparative Law, Inglaterra: Oxford University Press. 